\title{
V \\ A EDUCAÇÃO AMBIENTAL NO PROJETO POLÍTICO \\ PEDAGÓGICO DE UMA ESCOLA DO \\ NORTE DO PARANÁ*
}

\author{
Aline Sirlene de Souza \\ Jorge Sobral da Silva Maia
}

\section{Introdução}

Este estudo faz parte de uma pesquisa em desenvolvimento pela linha de pesquisa Práticas Docentes para a Educação Básica do Programa de PósGraduação em Educação - PPEd da Universidade Estadual do Norte do Paraná, Campus Jacarezinho, que tem como título "Educação ambiental crítica: concepções e práticas nos anos iniciais do ensino fundamental".

Com esta pesquisa, pretendemos investigar a presença da educação ambiental nos anos iniciais do ensino fundamental de um município do norte do Paraná, identificar as concepções e práticas dos professores em relação à Educação Ambiental. Além disso, pretendemos formar um grupo de estudos, juntamente com esses professores, para promover um espaço de discussões sobre a importância das práticas em educação ambiental que levem a reflexão e ampliem o conhecimento sobre a Educação Ambiental Crítica, assim como elaborar um documento tendo como ponto de partida os relatos dos professores pesquisados, sobre as dificuldades encontradas, para executar a Educação Ambiental Crítica e possibilidades para superar essas dificuldades.

Para tanto, consideramos que é importante compreender o local de pesquisa, conhecer onde a instituição se insere, e uma das formas se dá pela leitura do Projeto Político Pedagógico (PPP). Dessa maneira surge a seguinte

${ }^{*}$ DOI - 10.29388/978-65-86678-78-9-0-f.101-116 
questão de pesquisa: Como a educação ambiental está inserida no PPP de uma escola do norte do Paraná?

\section{Procedimentos metodológicos}

Para esse estudo, selecionamos o Projeto Político Pedagógico de uma das escolas escolhidas para a realização da pesquisa intitulada "Educação ambiental crítica: concepções e práticas nos anos iniciais do ensino fundamental". Esse documento é do ano de 2018 e está sendo revisto para adequação à Base Nacional Comum Curricular e Referencial Curricular do Paraná, portanto ao realizarmos a pesquisa anteriormente exposta, será necessária, uma nova análise do documento readequado para verificar se houve mudanças quanto às questões ambientais.

Utilizamos a pesquisa documental que, de acordo com Tozoni-Reis (2009, p. 41) "a busca de informações (dados) sobre os fenômenos investigados é realizada nos documentos, que exigem, para a produção de conhecimentos, uma análise." A análise de texto, nesse caso o Projeto Político Pedagógico, segundo Marconi e Lakatos (2003, p. 28) permite "observar os componentes de um conjunto, perceber suas possíveis relações, ou seja, passar de uma ideia-chave para um conjunto de ideias mais específicas, passar à generalização e, finalmente, à crítica."

Primeiramente, realizamos a leitura geral do documento, a fim de compreender sua organização e construção. Na sequência, buscamos como a Educação Ambiental se apresentava para analisá-la de acordo com o referencial teórico adotado. Cabe ressaltar que não nos detivemos a analisar os conteú dos, mas a concepção de educação ambiental nesse documento.

\section{A importância do projeto político pedagógico para escola}

O Projeto Político Pedagógico é uma exigência legal, um dos principais documentos que norteiam o trabalho da escola. Silva (2003, p. 296) define o PPP como um documento "elaborado coletivamente pelos sujeitos da escola e 
que aglutina os pensamentos políticos e filosóficos em que a comunidade acredita e os quais deseja praticar". A autora ainda acrescenta que nele se definem "os valores humanitários, princípios e comportamentos que a espécie humana concebe como adequados para a convivência humana" assim como "sinaliza os indicadores de uma boa formação e que qualifica as funções sociais e históricas que são de responsabilidade da escola" (SILVA, 2003, p. 296).

Nesse sentido, partimos do pressuposto de que o Projeto Político Pedagógico pode constituir-se como instrumento de luta e transformação social e se ele estiver permeado pela educação ambiental é possível que essa realidade também se manifeste na escola.

O Projeto Político Pedagógico é um documento previsto na Lei de Diretrizes e Bases da Educação, Lei 9394/96, em seus artigos 12, 13 e 14 que incubem os estabelecimentos de ensino de elaborar e executar sua proposta pedagógica, assim como salienta a participação dos docentes na construção dessa proposta. Por conseguinte, essa construção deve promover ações de gestão democrática, ou seja, se faz necessário a participação de toda comunidade escolar.

Paro (2005) afirma que a participação da comunidade na gestão escolar encontra inúmeros obstáculos, portanto há a necessidade de compreender a relevância dessa participação, não desistindo diante das primeiras dificuldades. Além disso, o autor salienta que a transformação da escola passa pela sua apropriação pelas camadas trabalhadoras, modificando a própria distribuição do trabalho no interior da escola.

Desse modo, a gestão democrática na escola articula-se com os interesses da sociedade, assim como é influenciada por aspectos econômicos, políticos, sociais. Mesmo com todos esses desafios e influências, a participação da comunidade escolar na elaboração do Projeto Político Pedagógico pode contribuir para a transformação social, desde que se incorpore nas dimensões do PPP o compromisso com a formação humana e construção da cidadania.

De acordo com Veiga (1998) o PPP, tem duas dimensões importantes, a dimensão política e a dimensão pedagógica. Em sua dimensão política compromete-se com a formação de cidadãos para um determinado tipo de socie- 
dade. Assim, no Projeto Político Pedagógico encontram-se as concepções de educação, sociedade, concepções estas que perpassam as relações sociais.

Na sua dimensão pedagógica possibilita que se efetive a intencionalidade da escola, definindo ações educativas. Segundo Veiga (1998, p. 13), essa intencionalidade deve ser de formar o cidadão "participativo, responsável, compromissado, crítico e criativo." Nesse sentido, o PPP contempla as propostas a serem desenvolvidas coletivamente guiadas por sua visão política, pois essas dimensões estão intrinsecamente ligadas.

Ao considerarmos a importância de suas dimensões compreendemos que a elaboração do Projeto Político Pedagógico não é simples, pois ao definir as intenções da escola e seus compromissos como instituição educacional, define-se também a teoria pedagógica que irá norteá-la. Dessa forma, se a escola deseja alterar a teoria que a norteia, não é suficiente apenas alterá-la no documento, como alerta Saviani (2011, p. 102):

Assim, quando se quer mudar o ensino, guiando-se por uma outra teoria, não basta formular o projeto pedagógico e difundi-lo para o corpo docente, os alunos e, mesmo, para toda a comunidade, esperando que eles passem a se orientar por essa nova proposta. É preciso levar em conta a prática das escolas que, organizadas de acordo com a teoria anterior, operam como um determinante da própria consciência dos agentes, opondo, portanto, uma resistência material à tentativa de transformação alimentada por uma nova teoria.

Desse modo, ao elaborar o PPP é importante o envolvimento de toda escola, propiciando situações para que a proposta possa ser construída em conjunto e não apenas como cumprimento às responsabilidades jurídicas. Entretanto, nem sempre o Projeto Político Pedagógico é construído em conjunto, possibilitando a participação da comunidade escolar. Todavia, ao buscarmos uma educação transformadora, há a necessidade de que diretores, coordenadores, professores, toda comunidade escolar e instâncias colegiadas sejam responsáveis por contribuir na tomada de decisões e, consequentemente, na meIhoria do ensino e da aprendizagem. 
Segundo Libâneo (2012, p. 251) é de responsabilidade de toda comunidade escolar assumir a construção do PPP e para que isso ocorra é necessário articular os segmentos que a compõe a fim de criar espaços de participação, e dessa forma a gestão estará a serviço dos objetivos educacionais. O autor aponta ações importantes a serem tomadas na elaboração do Projeto Político Pedagógico, como gestão participativa, formação continuada, formas de avaliação da escola e do desenvolvimento do projeto.

Nesse sentido, compreendemos a importância do Projeto Político Pedagógico para a escola e consequentemente para o trabalho educativo, pois ele "dará indicações necessárias à organização do trabalho pedagógico, que inclui o trabalho do professor na dinâmica interna da sala de aula." (VEIGA, 1998, p. 14). Dessa forma, é imprescindível pensar no papel da escola na garantia da apropriação pelos alunos dos conteúdos indispensáveis à sua formação.

\section{Práticas pedagógicas em educação ambiental no contexto escolar}

A escola tem um importante papel no desenvolvimento de práticas pedagógicas que priorizem os conteúdos elaborados pela humanidade, tendo o Projeto Político Pedagógico como norteador de suas ações. Segundo Saviani (2011, p. 14) ela existe "para propiciar a aquisição dos instrumentos que possibilitam o acesso ao saber elaborado (ciência), bem como o próprio acesso aos rudimentos desse saber. As atividades da escola básica devem organizar-se a partir dessa questão."

Ainda que haja certa clareza quanto à importância de seu papel, percebemos uma diversidade de fatores que, em alguma medida, dificultam e comprometem a formação integral dos estudantes, consequência de um crescente esvaziamento de conteúdos, contrapondo-se às atividades que podem ser transformadoras. Neste contexto, a educação também pode reproduzir as relações dominantes, como bem esclarece Loureiro (2019, p. 21):

A educação é uma dimensão indispensável do tornar-se humano. Por isso, sabendo ou não desse estatuto ontológico, em que o indivíduo só o é em sociedade, tanto se fala da educação como condição para qualquer 
transformação social. Contudo, enquanto um processo de socialização e aprendizado, é sempre oportuno lembrar que, ao mesmo tempo em que é indissociável dos movimentos transformadores, é igualmente elemento de reprodução das relações dominantes, uma vez que se realiza em sociedades determinadas e atende a certos fins quando é instituída.

Assim, é relevante compreender que a Educação Ambiental pode se apresentar de diferentes formas no contexto escolar, sustentadas por determinados interesses e que as concepções de Educação Ambiental inseridas no Projeto Político Pedagógico podem promover ações superficiais ou transformadoras.

Uma das formas em que a EA pode se apresentar no contexto escolar é a perspectiva fragmentada e conservadora, com vistas a resolver problemas pontuais, preocupada apenas com comportamentos individuais que deveriam ser aprendidos por todos, ignorando-se a relação sociedade e natureza. De acordo com Maia e Teixeira (2015, p. 299):

Nesse contexto, as questões referentes à EA têm pouco espaço na organização do trabalho na escola pública, sendo relegadas a projetos pontuais como datas comemorativas, além de outras tão fragmentadas quanto essas, levando à compreensão, por parte dos professores, gestores, estudantes e pais, que estas questões são secundárias no conteúdo escolar.

Nessa perspectiva "o processo educativo promove mudanças superficiais para garantir o status quo, a alteração de certas atitudes e comportamentos, sem que isso signifique incompatibilidade com o modelo de sociedade contemporânea em que vivemos." (LOUREIRO, 2003, p. 38). As práticas pedagógicas que consideram essa perspectiva preocupam-se com a transmissão de conhecimentos, como também repassar comportamentos padrões.

Encaixam-se nesta perspectiva atividades que tem um fim em si mesmas. Maia e Teixeira (2015, p. 294) entendem que:

$O$ relativismo, que por vezes encontramos em algumas práticas de $E A$, em nome de que "qualquer ação é válida", prejudica processos mais con- 
sistentes do ponto de vista sócio-histórico, em relação à educação escolar, em geral, e à EA especificamente. Consideramos estas ações como atitudes pontuais e fragmentadas do currículo, geralmente praticadas por meio de "comemorações" como o Dia da Árvore, Dia do Índio, Dia do Meio Ambiente, Dia da Água etc.

Por outro lado, ela pode se apresentar, em uma perspectiva que supere a dicotomia entre sociedade e natureza, como uma ação educativa que exige considerar o estudante como sujeito social, não havendo separação entre elas. Para Loureiro (2007, p. 67) sendo ela "uma prática social como tudo aquilo que se refere à criação humana na história, a educação ambiental necessita vincular os processos ecológicos aos sociais na leitura de mundo, na forma de intervir na realidade e de existir na natureza". Ainda, segundo o mesmo autor, para a Educação Ambiental Crítica não é possível uma prática escolar sem "o conhecimento da posição ocupada por educandos na estrutura econômica, da dinâmica da instituição escolar e suas regras e da especificidade cultural do grupo social com o qual se trabalha". Nesse sentido, no processo educativo deve-se considerar a complexidade das relações envolvidas nas questões ambientais, como explicitam Festozo e Tozoni-Reis (2014, p. 96) ao considerarem que:

A Educação Ambiental Crítica da forma como a compreendemos propõe
uma intervenção educativa democrática adequada, sendo capaz de abar-
car a complexidade das relações socioambientais, pois parte de uma con-
cepção natureza-sociedade como uma unidade dialética, que pretende
denunciar as dicotomias da ciência cartesiana e positivista e da socieda-
de capitalista (sociedade/natureza; esfera econômica/esfera social; men-
te/corpo; matéria/espírito, etc.).

Para que as práticas em Educação Ambiental no ensino formal contemplem essa complexidade de relações socioambientais superando a visão cartesiana e fragmentada, algumas ações são de grande importância. Loureiro (2005) aponta seis delas: 
(1) vinculação do conteúdo curricular com a realidade de vida da comunidade escolar; (2) aplicação prática e crítica do conteúdo apreendido; (3) articulação entre conteúdo e problematização da realidade de vida, da condição existencial e da sociedade; (4) projeto político-pedagógico construído de modo participativo; (5) aproximação escola-comunidade; (6) possibilidade concreta do professor articular ensino e pesquisa, reflexão sistematizada e prática docente. (LOUREIRO, 2005, p. 329)

Levando-se em conta as ações apontadas por Loureiro (2005), consideramos importante que o PPP contemple a educação ambiental, principalmente na perspectiva crítica, pois se ela estiver inserida na visão política da escola, construída coletivamente pelos interesses da comunidade escolar, possivelmente orientará as práticas pedagógicas tornando-as transformadoras, proporcionando aos estudantes um conhecimento emancipatório. Dessa maneira, as práticas no contexto escolar devem partir da compreensão da realidade e aspectos que envolvem os problemas ambientais, com objetivo de transformar essa realidade.

\section{A inserção da educação ambiental no projeto político pedagógico}

A Educação Ambiental é reconhecida como importante no ensino formal, há algum tempo, em diversos documentos nacionais, estaduais e municipais, considerada um eixo integrador no processo de formação. Dentre esses documentos podemos destacar: a Constituição Federal (1988) que estabelece em seu artigo 25 o direito ao meio ambiente, assim como a necessidade de promover a educação ambiental em todos os níveis de ensino, como também a conscientização pública para a preservação do meio ambiente:

Art. 225. Todos têm direito ao meio ambiente ecologicamente equilibrado, bem de uso comum do povo e essencial à sadia qualidade de vida, impondo-se ao Poder Público e à coletividade o dever de defendê-lo e preservá-lo para as presentes e futuras gerações.

(...) 
VI - promover a Educação Ambiental em todos os níveis de ensino e a conscientização pública para a preservação do meio ambiente.

A Política Nacional do Meio Ambiente (1981) também reforça a educação ambiental em todos os níveis do ensino, salientando sua presença inclusive na educação da comunidade, com o objetivo de capacitar para participação ativa na defesa do meio ambiente; a Política Nacional de Educação Ambiental (Lei n. 9.795, de 27 de abril de 1999), que afirma a educação ambiental como um componente essencial e permanente da educação formal.

Art. 2. A Educação Ambiental é um componente essencial e permanente da educação nacional, devendo estar presente, de forma articulada, em todos os níveis e modalidades do processo educativo, em caráter formal e não-formal.

Além destes, temos os Parâmetros Curriculares Nacionais, que tratam o tema meio ambiente integrado às áreas, de maneira transversal. Assim como as Diretrizes Curriculares Nacionais para a Educação Ambiental (Resolução CNE no 12/2012), que além de complementar a Política Nacional de Educação Ambiental trazendo os princípios e objetivos, indica formas de inserção da EA na Educação Básica e Ensino Superior:

Art. 16. A inserção dos conhecimentos concernentes à Educação Ambiental nos currículos da Educação Básica e da Educação Superior pode ocorrer:

I - pela transversalidade, mediante temas relacionados com o meio ambiente e a sustentabilidade socioambiental;

II - como conteúdo dos componentes já constantes do currículo;

III - pela combinação de transversalidade e de tratamento nos componentes curriculares. Parágrafo único. Outras formas de inserção podem ser admitidas na organização curricular da Educação Superior e na Educação Profissional Técnica de Nível Médio, considerando a natureza dos cursos. 
No que se refere a Educação Infantil e Ensino Fundamental, recentemente temos a Base Nacional Comum Curricular (BNCC, 2018), um documento normativo que estabelece aprendizagens essenciais a serem desenvolvidas na Educação Básica. A BNCC ressalta os documentos e resoluções anteriores e trata a Educação Ambiental como um dos Temas Contemporâneos Transversais, a serem inseridos nos documentos curriculares.

Em âmbito estadual, o Paraná elaborou o Referencial Curricular do Paraná, estabelecendo objetos de conhecimento e objetivos de aprendizagem. Este documento tem por base a BNCC, porém considera as especificidades do estado. Ainda com relação ao estado do Paraná, como complementação ao referencial, elaborou-se o Currículo da Rede Estadual Paranaense (CREP). Neste documento os conteúdos foram divididos de acordo com os trimestres, com o objetivo de que essa organização fortaleça o processo de ensino-aprendizagem. Porém, ao estabelecer e definir os conteúdos e período para que sejam desenvolvidos, o CREP pode diminuir a autonomia das escolas na definição de suas propostas curriculares.

Essas leis e documentos salientam a importância de que a Educação Ambiental se faça presente no âmbito escolar, entretanto, se a elaboração do PPP for guiada apenas por eles pode ocorrer uma incorporação superficial dessa temática. Assim, eles devem ser analisados coletivamente na construção do Projeto Político Pedagógico, estabelecendo adequações a fim de que esse documento contemple a realidade de cada escola, ou seja, que se considere suas características e especificidades.

Dessa forma, a inserção da Educação Ambiental no PPP da escola pode contribuir para que as práticas educativas nessa temática colaborem para a formação humana integral, considerando todos os aspectos de ordem cultural, social, econômica e política. De acordo com Tozoni-Reis (2008) ao refletir sobre a EA na escola é preciso pensar nas relações entre educação, escola e sociedade. Para a autora, o processo educativo é um processo de formação humana, ou seja, nele os seres humanos são produzidos, construídos, como humanos.

Entretanto a educação escolar pode manter ou alterar as relações sociais historicamente construídas, assim é necessário compreender as práticas 
pedagógicas derivadas das intencionalidades expostas no PPP, bem como entender que a educação ambiental pode se apresentar de diferentes formas no contexto escolar, e que a concepção inserida na proposta pedagógica pode ser instrumento de transformação da sociedade ou de manutenção de interesses hegemônicos.

O projeto político pedagógico analisado apresenta poucas linhas sobre Educação Ambiental. Nele, a questão ambiental é considerada "como cada vez mais urgente e importante para a sociedade, pois o futuro da humanidade depende da relação estabelecida entre a natureza e o uso pelo homem dos recursos naturais disponíveis." (PPP, 2018, p. 162).

Percebemos que o ambiente no PPP é tratado como "recursos naturais", dessa forma difere-se do referencial adotado para este trabalho por não considerar as dimensões sociais. Segundo Loureiro (2003) quando os programas educativos "por dissociarem o ambiental do social e retirarem a historicidade da atividade humana, podem conduzir a um idealizado e acrítico consenso sobre as causas e soluções dos problemas ambientais." (LOUREIRO, 2003, pp. 51-52).

O PPP menciona a Lei 9.795 de 27 de abril de 1999, que estabelece que a Educação Ambiental deve estar presente, de forma articulada, em todos os níveis e modalidades do processo educativo, em caráter formal e não-formal e afirma "a importância de se incluir a temática do Meio Ambiente, permeada em toda prática educacional." (PPP, 2018, p. 162).

Para Loureiro (2007, p.71) "é preciso, no âmbito escolar, conseguir a inserção da educação ambiental no projeto político-pedagógico e a consolidação de espaços de participação institucionais [...] nas quais a discussão ambiental pode ser inserida e potencializada."

De acordo com o PPP os projetos desenvolvidos na escola, tanto de Educação Ambiental, quanto de outros temas "trabalham, de maneira contextualizada, enfatizando certos temas que fazem necessários à realidade da escola em momentos específicos e, desenvolvendo outros temas durante todo o ano letivo." (PPP, 2018, p.51). Apesar de mencionar que a escola desenvolve projetos de Educação Ambiental, notamos que esses projetos, atividades e ou- 
tras ações, não estão expostos no PPP, dessa forma não foi possível identificar somente pela leitura, a concepção de Educação Ambiental inerente a eles.

\section{Conclusões}

Diante do exposto, identificamos a importância da Educação Ambiental estar inserida no Projeto Político Pedagógico, considerando todos os aspectos que envolvem os problemas ambientais, em uma perspectiva de totalidade. Dessa forma, salientamos a necessidade de que a construção do PPP priorize ações de gestão democrática, propiciando a participação de toda comunidade escolar em sua construção.

Em uma análise inicial do Projeto Político Pedagógico de uma escola dos Anos Iniciais do Ensino Fundamental do Norte do Paraná, verificamos a presença da educação ambiental, porém de maneira fragmentada, não a relacionando ao contexto histórico e social, considerando o ambiente como "recursos naturais," e não por seu valor intrínseco.

Do mesmo modo, ainda que mencione desenvolver projetos e atividades de Educação Ambiental, elas não se apresentam explicitamente no documento. Assim, faz-se necessário ir a campo para verificar em que medida isso se apresenta na realidade escolar, assim como qual a concepção adotada nesses projetos e atividades desenvolvidas pelos docentes no intuito de perceber se há uma contradição entre o que se apresenta no documento, e o que é efe tivamente é realizado.

Por fim, cabe ressaltar a importância das práticas pedagógicas fundamentadas nos conhecimentos construídos historicamente pela humanidade, a fim de proporcionar aos estudantes um conhecimento emancipatório, garantindo a participação e controle social da comunidade escolar e tendo a Educação Ambiental como um eixo integrador no processo ensino aprendizagem, inserida no Projeto Político Pedagógico. 


\section{Referências}

BRASIL. Lei de Diretrizes e Bases da Educação Nacional. Lei № 9394, 20 de dezembro de 1996.

BRASIL. Lei n. 9.795 de 27 de abril de 1999. Dispõe sobre a educação ambiental, institui a Política Nacional da Educação Ambiental. Brasília, DF, 27 dez. 199. Disponível em: www.planalto.gov.br/ccivil_03/leis/L9795.htm. Acesso em: 09 Fev. 2020

BRASIL. Resolução CNE/CP 2/2012. Diário Oficial da União, Brasília, 18 de junho de 2012 - Seção 1, p. 70.

BRASIL. Secretaria da Educação Fundamental. Parâmetros Curriculares Nacionais: Meio Ambiente. Secretaria de Educação Fundamental. Ministério da Educação e do desporto: Brasília: MEC/SEF, 1997. Disponível em: http://portal.mec.gov.br/seb/arquivos/pdf/meioambiente.pdf. Acesso em: 09 Fev. 2020

FESTOZO, Marina Battistetti; TOZONI-REIS, Marília Freitas de Campos. Ambientalização Curricular no Ensino Superior: Problematizando a Formação de Educadores Ambientais. In: TOZONI-REIS, Marília Freitas de Campos, MAIA, Jorge Sobral da Silva (Orgs.) Educação ambiental a várias mãos: educação escolar, currículo e políticas públicas. 1. ed. - Araraquara, SP: Junqueira\&Marin, 2014.

LIBÂNEO, José Carlos. Educação escolar: políticas, estrutura e organização. 10. ed. rev. e ampl. - São Paulo: Cortez, 2012. - (Coleção docência em formação: saberes pedagógicos / coordenação Selma Garrido Pimenta)

LOUREIRO, Carlos Frederico Bernardo. Educação ambiental crítica: contribuições e desafios. In: MELLO, S.; TRAJBER, R. (Org.). Vamos cuidar do Brasil: conceitos e práticas em educação ambiental. 1 ed. Brasília: MEC/UNESCO, 2007, v. 1, p. 65-73. 
LOUREIRO, Carlos Frederico Bernardo. Educar, participar e transformar em educação ambiental. In: Revista brasileira de educação ambiental - n. 0 (nov.2004). - Brasília: Rede Brasileira de Educação Ambiental, 2004.

LOUREIRO, Carlos Frederico Bernardo. Premissas teóricas para uma educação ambiental transformadora. In: Ambiente e Educação, n. 8, p. 37-54, Rio Grande, 2003.

LOUREIRO, Carlos Frederico Bernardo. Teoria Crítica. In: FERRARO Jr. Luiz Anto(Org.) Encontros e Caminhos: Formação de Educadoras(es) Ambientais e Coletivos Educadores. Brasília, MMA, Diretoria de Educação Ambiental, 2005.

MAIA, Jorge Sobral da Silva; TEIXEIRA, Lucas André. Formação de professores e educação ambiental na escola pública: contribuições da pedagogia históricocrítica. Revista HISTEDBR On-line, Campinas, v. 15, n. 63: 293-305. Disponível em: https://periodicos.sbu.unicamp.br/ojs/index.php/histedbr/article/view/ 8641185. Acesso em 29 Jan. 2020.

MARCONI, Marina de Andrade. LAKATOS, Eva Maria. Fundamentos de metodologia científica. São Paulo: Atlas, 2003. 5 ed.

PARO, Vitor Henrique. Gestão Democrática da Escola Pública. São Paulo, Ática, 2005.

PROJETO POLÍTICO PEDAGÓGICO, 2018.

SILVA, Maria Abádia da. Do projeto político do Banco Mundial ao projeto político-pedagógico da escola pública brasileira. Cadernos CEDES, n.61 Campinas dez. 2003

TOZONI-REIS, Marília Freitas de Campos. Educação Ambiental no Brasil. Salto para o futuro, ano XVIII, boletim 01, mar. 2008. 
TOZONI-REIS, Marília Freitas de Campos. Metodologia da pesquisa. 2a ed. Curitiba: IESDE, 2009.

SAVIANI, Dermeval. Pedagogia histórico-crítica: primeiras aproximações. 11. ed. rev. - Campinas, SP: Autores Associados, 2011. - (Coleção educação contemporânea)

VEIGA, Ilma Passos da. Projeto político-pedagógico da escola: uma construção coletiva. In: VEIGA, IIma Passos da (org.). Projeto político-pedagógico da escola: uma construção possível. Campinas: Papirus, 1998. p.11-35. 
